\title{
CONCEPTISMO E PICARESCA EM EL BUSCONN DE QUEVEDO
}

\section{Mario Miguel González}

O conceptismo, antes de mais nada, é um estilo literário, isto é, uma maneira peculiar (predominante em alguns escritores de uma época neste caso) de se criar a obra de arte literária, uma maneira de se combinar elementos verbais selecionados segundo critério sistematizável. A picaresca, por sua parte, é, antes de mais nada, uma atitude ante a vida e uma maneira de ver o mundo através dos protagonistas de certas obras literárias que agrupamos, precisamente, em razão dessa atitude e dessa visão peculiar. O encontro mais feliz de ambas as formas se deu na obra que fecha a série clássica das novelas picarescas: El Buscón, de don Francisco de Quevedo, o escritor que mais longe levou os princípios do conceptismo, ao menos na narrativa.

O conceptismo, reverso (ou anverso, tanto faz) da medalha barroca, pretendia desprezar o artifício da metáfora culterana criadora de supra-realidades e enveredou pelos artifícios da agudeza, dos conceitos. Para surpreender o leitor - objetivo inegável de toda a arte barroca - o conceptista parte à procura de palavras novas criadas da associação das pré-existentes, utiliza as palavras simultaneamente com dois ou mais de seus significados, outorga-lhes significados arbitrários, violenta a sintaxe, chegando, por outras vias, aos mesmos artificiosos resultados que condenava nos odiados culteranos, já que, na frase de B. Croce, as lutas de gongoristas e conceptistas não passavam de "brigas de família"

A necessidade de ser agudo na expressão consagrou recursos de jogo verbal, tais como o equívoco, a paronomásia, a antimetábole, o paralelismo, a gradação, a antítese, o paradoxo e todo tipo de contraste.

De outra parte, uma série de recursos ajudavam para adensar o mundo dos conceitos: a acumulação, a hipérbole, a prosopopéia, o zeugma, a elipse, até obter a saturação da expressão verbal. Esta, por sua vez, devia condensar-se ao máximo para obter melhor o efeito procurado. Daí o laconismo da frase que, aumentando a dificuldade 
da compreensão, proporcionava maior prazer ao leitor na hora da descodificação do verdadeiro "enigma" assim proposto. E o ritmo da frase tornava-se cortado e veloz.

A profundeza do pensamento e o caráter lúdico do conceptismo levaram-no a ser o veículo ideal de dois "gêneros" literários: o burlesco e o didático-moral; o jogo verbal levou à burla e à sátira; e o ornamento verbal mascarou a intenção didática e conseguiu, assim, amenizar a lição moral.

Por outro lado, em meados do século XVI, uma pequena obra, hoje anônima, deixava de lado os mundos fabulosos de cavaleiros e pastores, de mouros ideais e bizantinas peripécias, para se fixar no mundo imediato onde mendigos cegos, fidalgos desempregados, frades avaros ou vigaristas mostravam maneiras não muito dignas de se manter ou ascender na escala social; a ascensão começava para muitos, como para o protagonista da pequena obra, na solução do primeiro e elementar problema de matar a fome. Lazarillo de Tormes traçava assim as linhas básicas do gênero que iria se chamar de "picaresca" Basicamente, o pícaro era, no seu berço literário, alguém que brotava dos mais baixos estratos econômico-sociais e que, em forma itinerante, devia aprender a sobreviver num meio hostil, no submundo de suas funções de criado de sucessivos amos. Tudo isso foi dado em forma de experiência transmitida ao leitor a partir de seu próprio ponto de vista. Assim, o relato será autobiográfico e, com tudo isso, o germe primeiro em volta do qual o romance moderno iria construir um mundo próprio - a "personagem" da narativa fazia sua primeira aparição na literatura. Já não haveria arquétipos novelescos a serem obedecidos, cavaleiros forçados a triunfar. Pela primeira vez alguém dizia "eu" num relato com a plena autonomia do ente literário. Esse "eu" seria, antes de mais nada, olhos para contemplar e descrever um universo pessoal, que já não podia ser o falso e convencional mundo das novelas da época, de puras abstrações. O mundo era agora experiência pessoal e por isso mesmo, experiência dolorosa que exigia opções do protagonista. O pícaro deve traçar seu destino, não mais em busca de ideais utópicos de cavaleiro, porém à procura do pedaço de pão imprescindível para ele mesmo nesse momento.

Daí o defrontar-se a cada passo con uma sociedade que o obriga a ganhar esse pão, sem mais armas que seu próprio engenho. E o itinerário, através da sociedade hostil, dá o retrato hostil - até certo ponto - da sociedade, no Lazarillo de Tormes. Lázaro, contudo, não vai além da ironia na descrição de seu lar, de seus amos, dessa sociedade em que acabará por diluir-se ao aceitá-la finalmente e integrar- 
se nela. Vê o mundo no espelho plano e simples de sua ingênua malícia.

O século XVII, porém, estava na virada daquela perigosa "crista" (como Wölffin define a Renascença) e a decepção do homem barroco com aquela sociedade tão distante dos mágicos ideais até aí alimentados - e que Lázaro já havia posto em evidência — provocaria a vertiginosa descida, o chamado "desengaño" que marcaria profundamente toda literatura desse século.

Daí por diante, os herdeiros de Lázaro de Tormes não mais poderiam limitar-se à crítica risonha de seu contexto social: a aventura do pícaro avançaria para a delinquiência precoce; a experiência iria levá-lo ao pessimismo, à desconfiança e ao ressentimento. Em decorrência, as duas vertentes do conceptismo que antes assinalávamos - a sátira e a moralidade - encheriam a maioria das páginas do mais ilustre sucessor de Lázaro: "Guzmán de Alfarache", de Mateo Alemán, e, logo depois, dos seus muitos congêneres.

Assim, aparecem agora as famosas refleões moralizantes após cada trapaça que levam à exposição da norma correspondente transgredida. A sátira ganha violenta acritude; o humano carrega-se de pessimismo; a realidade começa a ser vista, não mais com a simplicidade do ingênuo Lázaro, porém carregada do profundo ressentimento que a limita a seus aspectos infra-humanos. A linguagem ideal para construir esse universo estava no lúdico e profundo conceptismo. E o maior narrador conceptista, don Francisco de Quevedo Villegas, escreveu assim La vida del buscavida, por otro nombre don Pablos, mais tarde por ele mesmo titulada Historia de la vida del Buscón llamado don Pablos, ejemplo de vagamundos y espejo de tacaños. Esse espelho já era o espelho côncavo da "calle del Gato" onde seria obtida a começos do século $\mathrm{XX}$, a visão esperpêntica da realidade por Ramón del Valle-Inclán e nele dava-se a hipérbole do pícaro, ou seja, nas palavras de Samuel Gili Gaya, que copia o jogo verbal de Quevedo, nascia o "protopícaro" (1)

Porém, Quevedo havia escrito o seu Buscón muito antes de sua impressão em 1626; possivelmente entre 1601 e 1603, de acordo com F Lázaro Carreter (2) (que analisa todas as teorias anteriores a respeito da data), isto é, entre os 21 e 23 anos de sua idade. Longe estava ainda de pensar em seus tratados ascéticos ou de suas obras políticas. Era a época festiva de suas fantasias satíricas. E Quevedo

(1) GILI GAYA, Samuel: "Apogeo y desintegración de la novela picaresca" in Historia general de las literaturas hispánicas (dir.: Guillermo Díaz Plaja). Barcelona, Barna, 1953, tomo III, p. XVI.

(2) LÁZARO CARRETER, Fernando: "Originalidad del Buscón" in Es- 
não estava ainda possuído da inquietação didático-moralizante; apenas a sátira burlesca dominava sua criação; aí nasceu o Buscón. Nascia sob a influência direta do Guzmán de Alfarache, de 1599, que fixava o gênero segundo o padrão a que nos referimos. Como deixa claro Gili Gaya no excelente estudo acima citado, muita coisa do Guzmán e da literatura anterior iria refletir-se no Buscón:

"Aldonza, madre de Pablos el Buscón, es evidentemente Celestina; el domine Cabra tiene su antecedente en el clérigo avariento del Lazarillo; las sisas del ama que tenían los estudiantes en Alcalá, y otros pormenores de la vida estudiantil, son clara reelaboración del Guzmán de Alfarache; en la misma obra se halla también la fuente de las argucias de los mandigos de Madrid" (3).

Quevedo, porém, soube eliminar o menos valioso de seu modelo imediato e recriar vigorosamente o que o anônimo pícaro primeiro lhe sugeria. Daí não haver digressões moralizantes enfadonhas no Buscón, como não há desagregadoras estórias intercaladas. O conceptismo de Quevedo não se desgasta em carregar uma novela que devia ser feita à base de acumulação de episódios; como não se perde na descrição detalhada. Aproxima-se nisto, claramente, do Lazarrillo. Diz Gili Gaya:

"El Lazarillo y el Buscón suelen preferir el rasgo sintético sobrio e intenso. Pero así como en el Lazarillo está logrado con cierto primitivismo ingenuo, como adivinación intuitiva certera, en Quevedos es el resultado de profunda elaboración mental (4).

A intencionalidade de Quevedo vai à procura do grotesco, do esperpêntico, onde a fantasia pode multiplicar hiperbolicamente a dimensão do mundo pícaro. Como consequiência, a visão da sociedade dividida em dois planos no Lazarillo - o do pícaro e o dos amos é anulada mediante sua transformação num único submundo de "bellacos" onde o único horizonte de Pablos é chegar a "ser bellaco con los bellacos y más que todos, si más pudiese" (5) Isto se diz exatamente no momento em que a noção de amo desaparece no livro, no começo do capítulo VI; com raras exceções, daí em diante apenas veremos "bellacos" em volta de Pablos. E esse submundo está retratado a partir das imagens que acentuam a visão burlesca do conceptista: o equívoco, a antítese, o paradoxo, a prosopopéia e, acima de tudo, a hipérbole que provoca a máxima deformação, dificultando a rela-

tilo barroco y personalidad creadora. Madrid, Cátedra, 1974, p. 82-5.

(3) GILI GAYA, Samuel: op. cit., p. XIV

(4) Idem, ibidem, p. XV

(5) QUEVEDO, Francisco de: El Buscón. Madrid, Espasa-Calpe, 1960,

Col. Clássicos Castellanos, cap. VI, p. 69. 
ção com qualquer referente, físico ou cultural. E estes recursos acumulam-se até a saturação.

Assim, a obra se define para nós barroquíssima pelo exagero que parece nortear a pena quevediana. Citando, mais uma vez, Gili Gaya,

"si se trata de realismo, Quevedo no vacila en llegar al naturalismo más repugnante, no igualado por ninguna otra novela picaresca. En la sátira llegará al sarcasmo más cruel. En el chiste, a las ingeniosidades más descoyuntadas. ( . .) Convengamos que la desmesura va bien al género picaresco, y éste fue el gran acierto de Quevedo al tomarlo en sus manos y reelaborarlo. No se contentó con un pícaro cualquicra, sino que quiso crear El Gran Tacaño, es decir, el gran bellaco del fraude" (6)

Em resumo: o escritor conceptista, em geral, achou, principalmente, duas vertentes para seu estilo: a da sátira e a do didático-moral. A picaresca nascida anteriormente em direção à sátira carregase no século XVII do peso do moralismo (como, por outra parte, iria desviar-se para a novela de aventuras, à força de estender o itinerário do protagonista) $\mathrm{O}$ conceptismo quevediano sabe que o efeito satírico será maior, quanto maior a condensação; e lança mão de todos os recursos que adensem a exposição, fazendo com que o valor semântico de cada palavra se multiplique, seja por jogar com equívocos que nascem da polissemia verbal, seja por aproximar contrários que assim vêem reforçada sua significação (em paronomásias, antimetáboles, paralelismos, gradações, antíteses e paradoxos), seja por personificar inesperados elementos ou dar dimensões hiperbólicas asu acriaturas, seja por condensar a frase mediante a elipse e o zeugma. Todos estes recursos são facílimos de serem achados no Buscón, a cada passo. No entanto, parece evidente (e faltaria um estudo sistemático do assunto) que Quevedo não perdeu oportunidade de ser "conceptista" ao máximo, nos primeiros capítulos. Mais adiante, porém, deixa-se levar pela figura de seu anti-herói e parece esquecer seu intento inicial.

Os recursos literários do conceptismo e sua resultante, a saturação verbal, constituem o fator retórico através do qual Quevedo formaliza um fator ideológico constituido pelos traços definitórios da picaresca, acima apontados. Essa formalização resulta numa caricatura . reside a base do "esperpento" que, através de Goya, formula Valle-Inclán no século XX, fundamentalmente na medida em que a intensificação do fator retórico produz, entre outras coisas, uma deformação sistemática e degradante da realidade e a sátira permanente.

(6) GILI GAYA, Samuel: op. cit., p. XV-XVI. 
Como nos "esperpentos", no Buscón de Quevedo dá-se a denúncia social, mesmo que não apareça explicitamente formulada. El Buscón é uma obra de engenho; porém não deixa de ser uma descomunal visão "esperpéntica" de uma realidade, o submundo dos "bellacos" Nessa visão, anula-se qualquer outra realidade superior que possa entenderse como o ideal procurado pelos "bellacos"; isto implica na redução da sociedade - a do leitor do século XVII ou do século XX - a um mundo de "bellacos" Enquanto que no Lazarillo o protagonista luta até conseguir sair da condição de criado de alguém e não mais passar fome, Pablos, cheio do dinheiro da herança paterna, se mistura propositalmente entre os "buscones" madrilenhos para cumprir seu propósito de ser "bellaco con los bellacos, y más que todos si más pudiese"

Quevedo soube evitar a teorização paralela, isto é, não tıra explicitamente exemplos dos fatos que narra, muito mais quando sua intenção evidente é não contrastar dois universos opostos, e sim, carregar as tintas do submundo picaresco onde não cabiam lições, a não ser as da "bellaquería" E assim, sem desprezar os achados de seu antecessor, Guzmán de Alfarache, amplifica o submundo do Lazarillo.

A picardia encontrou nos recursos conceptistas do satírico Quevedo o melhor veículo para chegar à sua expressão mais densa, mais rica e mais cheia das surpresas que ainda hoje atingem seu objetivo de provocar uma resposta por parte do leitor 